\title{
An Analysis of the Forces Required to Drag Sheep over Various Surfaces
}

\author{
J.T. Harvey ${ }^{a^{*}}$, J. Culvenor $^{\mathrm{b} 1}$, W. Payne ${ }^{\mathrm{c}}$, S. Cowley ${ }^{\mathrm{d}}$, M. Lawrance ${ }^{\mathrm{c}}$, \\ D. Stuart ${ }^{e} \&$ R. Williams ${ }^{\mathrm{f}}$
}

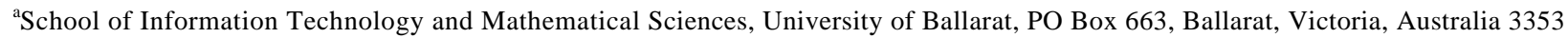 \\ ${ }^{\mathrm{b}}$ VIOSH Australia, University of Ballarat, PO Box 663, Ballarat, Victoria, Australia 3353 \\ Current contact address: John Culvenor, 40 Wilfred Road, East Ivanhoe, Victoria, Australia, 3079 \\ ${ }^{\mathrm{c} S}$ School of Human Movement and Sport Sciences, University of Ballarat, PO Box 663, Ballarat, Victoria, Australia 3353 \\ ${ }^{\mathrm{d}}$ VIOSH Australia, University of Ballarat, PO Box 663, Ballarat, Victoria, Australia 3353 \\ ${ }^{\mathrm{e}}$ School of Physical Education, Exercise and Sport Studies, University of South Australia, Holbrooks Road, Underdale, South Australia, Australia, \\ 5032 \\ ${ }^{\mathrm{f}}$ Wimmera Health Care Group, Physiotherapy Department, Baillie Street, Horsham, Victoria, Australia, 3400
}

\begin{abstract}
Some occupational health and safety hazards associated with sheep shearing are related to shearing shed design. One aspect is the floor of the catching pen, from which sheep are caught and dragged to the shearing workstation. Floors can be constructed from various materials, and may be level or gently sloping. An experiment was conducted using eight experienced shearers as participants to measure the force exerted by a shearer when dragging a sheep. Results showed that significant changes in mean dragging force occurred with changes in both surface texture and slope. The mean dragging forces for different floor textures and slopes ranged from $359 \mathrm{~N}$ ( $36.6 \mathrm{~kg}$ ) to $423 \mathrm{~N}$ (43.2kg), and were close to the maximum acceptable limits for pulling forces for the most capable of males. The best floor tested was a floor sloped at 1:10 constructed of timber battens oriented parallel to the path of the drag, which resulted in a mean dragging force $63.6 \mathrm{~N}(15 \%)$ lower than the worst combination.
\end{abstract}

Keywords: Sheep shearing; ergonomics; biomechanics; psychophysics; pulling

\section{Introduction}

Sheep shearing is an arduous occupation involving a range of physically demanding tasks: catching and tipping the sheep, dragging the sheep into position, fleece removal, and guiding the shorn sheep away. Shearing has proved difficult to mechanise, and still has significant occupational hazards involving manual handling (Australian Workers' Union (Vic.), 1993; Health and Safety Organisation, Victoria, 1995; National Occupational Health and Safety Commission, 1990). Cole and Foley (1995) reported that injuries to shearers included fractures and sprains (66.4\%), musculoskeletal injuries $(15.0 \%)$, and contusions/burns $(8.5 \%)$. The most common bodily location for these injuries was the hand, finger and thumb (22\%) and back $(19.0 \%)$. Back injuries were reported at a frequency of 100.6 cases per 1,000,000 hours worked. According to Culvenor et al. (1997), Australian shearers suffer injuries at six times the all-industry average (per worker or per hour) and injuries are on average between $70 \%$ and $140 \%$ more costly than in other industries. Other studies have confirmed that shearing is intensive in terms of its energy demand (Stuart, 1991; Webster \& Lush, 1991).

In the study of which the work reported in this paper formed part (Payne, et al. 1998), industry focus groups identified the effort required to drag sheep as an issue, indicating that many shearers suffered back injuries during sheep dragging. Alternative sheep delivery systems such as elevated races (Freeman, 1991) eliminate dragging, but require substantial financial investment. This study focussed on identifying simple and inexpensive ways to reduce risks, and to quantify the impact of these methods in order to encourage their adoption.

In response to acknowledged association with lowback pain (Hoozemans et al. 1998), occupational dragging tasks have been investigated in construction workers (Hoozemans, et al. 2001), postal workers (Van der Beek et al. 2000) and aircraft loaders (Looze and Urlings, 2001), but not previously in shearers. In an

* Corresponding author. Te.: +613-53279273

E-mail address: j.Harvey@ballarat.edu.au (J.T. Harvey).

${ }^{1}$ Current address: John Culvenor, 40 Wilfred Road, East Ivanhoe, Victoria, 3079, Australia, j.culvenor@culvenor.com.

Note: This paper is John Culvenor's version reprinted at www.culvenor.com with permission of Elsevier Science. There may be slight variations (pagination, typographical, etc) between this version and the published version (Applied Ergonomics, vol. 33, pp. 523-531). 
early study, Ayoub and McDaniel (1974) observed maximum isometric forces exerted during pulling of $311 \mathrm{~N}$ for males and $267 \mathrm{~N}$ for females. Chaffin et al. (1983) allowed participants to assume postures commonly adopted during work tasks, such as placing the feet apart, and reported maximum isometric pull forces of $370 \mathrm{~N}$ for males and $180 \mathrm{~N}$ for females. The use of isometric tasks restricted the applicability of such results, as Lee et al (1991) reported that subjects assume different postures in static and dynamic pulling tasks. Kumar et al (1988) reported that the strength exerted during dynamic tasks was generally less than that exerted during static or isometric tasks. The limitation of maximum pulling forces in industrial situations requiring repeated submaximal effort was recognised by Ciriello et al (1990), who reported that the maximum force that can be exerted over a period of hours without fatigue was $400 \mathrm{~N}$ for males and $200 \mathrm{~N}$ for females. In addition to limiting pulling forces, avoidance of back injury also requires knowledge of the forces acting on the spine; particularly at the L5/S1 spinal disc. For example, Lee et al. (1991) reported that L5/S1 compression varied with handle height during pulling, with compression being lowest at a handle height of $109 \mathrm{~cm}$.

Shearing involves repeated loading of the tissues of the low back to apparently submaximal levels. McGill (1997) reported that cumulative trauma from subfailure magnitude loads causes a slow degradation of the failure tolerance due to the prolonged stoop posture loading the posterior ligaments of the spine and posterior fibres of the intervertebral disc, causing creep deformation, possibly to the point of micro-failure. It is possible that failure tolerance is reduced by repeated stooping during shearing, rendering the shearer more susceptible to back injury when dragging.

The aim of the current study was to examine the range of floor surfaces and angles identified by industry focus groups, and to determine the combination of floor surface and angle which minimized the forces required during sheep dragging. A second aim was to assess the forces measured in comparison to those considered acceptable from a health and safety perspective.

\section{Methodology}

\subsection{Subjects}

The study involved eight male shearers, as described in Table 1, and five sheep. The data were collected on two days, with four shearers attending on each day. The sheep weighed $50-55 \mathrm{~kg}$ and had approximately eight months' wool. Shearers gave their informed consent to participate and the study was approved by the ethics committee of the University of Ballarat.
Table 1

\begin{tabular}{cccc} 
Subject Details & & & \\
\hline Shearer & Height $(\mathrm{cm})$ & Mass $(\mathrm{kg})$ & $\begin{array}{c}\text { Full-Time/ } \\
\text { Part Time }\end{array}$ \\
\hline 1 & 194 & 87 & PT \\
2 & 178 & 72 & FT \\
3 & 185 & 97 & PT \\
4 & 178 & 76 & FT \\
5 & 178 & 85 & FT \\
6 & 182 & 101 & PT \\
7 & 182 & 110 & FT \\
8 & 172 & 82 & PT \\
\hline Mean & 181 & 89 & \\
SD & 6.5 & 13 & \\
\hline
\end{tabular}

\subsection{Experimental factors: floor surfaces and slopes}

Five types of flooring material were investigated:

1. Wood battens oriented parallel to the drag.

2. Wood battens oriented at right angles to the drag.

3. Plastic battens oriented parallel to the drag.

4. Plastic battens oriented at right angles to the drag.

5. Steel mesh.

The wood battens (Figure 1a) were $45 \mathrm{~mm}$ wide with a $15 \mathrm{~mm}$ gap, chamfered to mimic the profile of a worn batten. The plastic "battens" (Figure1b) were tiles $800 \mathrm{~mm}$ by $400 \mathrm{~mm}$, with slots that gave a directional character. The steel mesh (Figure 1c) was woven of $5 \mathrm{~mm}$ wire with square holes at $25 \mathrm{~mm}$ centres. The floor slopes tested were horizontal $\left(0^{\circ}\right)$ and 1:10 $\left(5.6^{\circ}\right)$.

Interchangeable sections of flooring were constructed from each of the five materials, and with both slopes. The sections could be attached to a force plate, together with matching panels in front of and behind the force plate. (See Figure 2.)

\subsection{Experimental design}

The combination of the two factors (five surfaces, two slopes) with each of the five sheep resulted in a repeated measures design with 50 trials for each of the eight shearers, or 400 trials in all. The order of the experiment was randomised within some practical constraints. Time-consuming slope changes were minimised, with no slope in the morning of day one and with the slope in the afternoon. This order was reversed on day two. Within each session, a random order of textures was used, then a random order of sheep, and lastly a random order of shearer. This schedule minimised the chance of any shearer undertaking two trials in succession. On the few occasions that this occurred, a rest period of a least three minutes separated the trials to minimise the potential confounding effect of fatigue. 


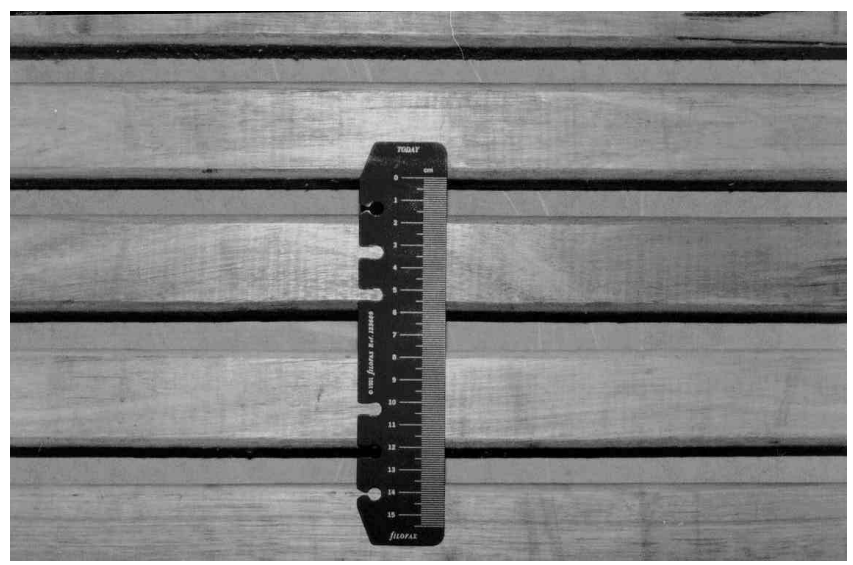

(a)

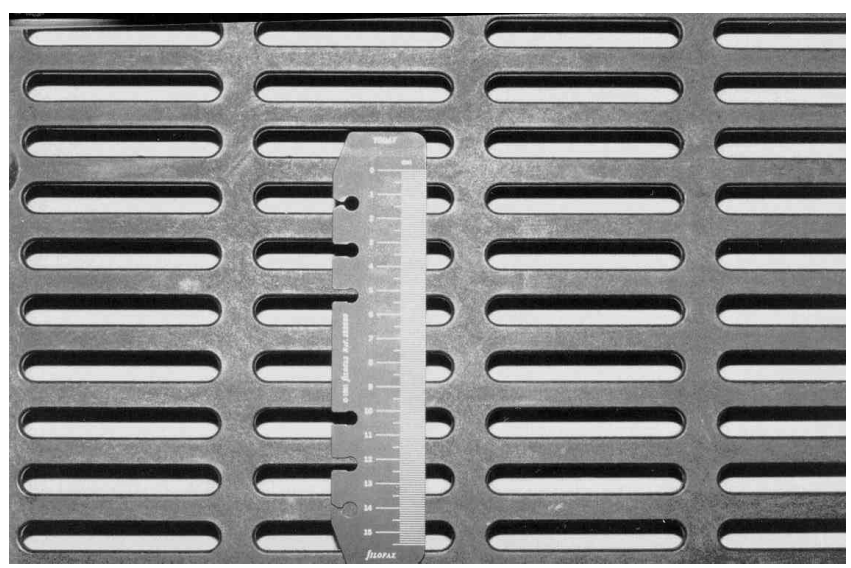

(b)

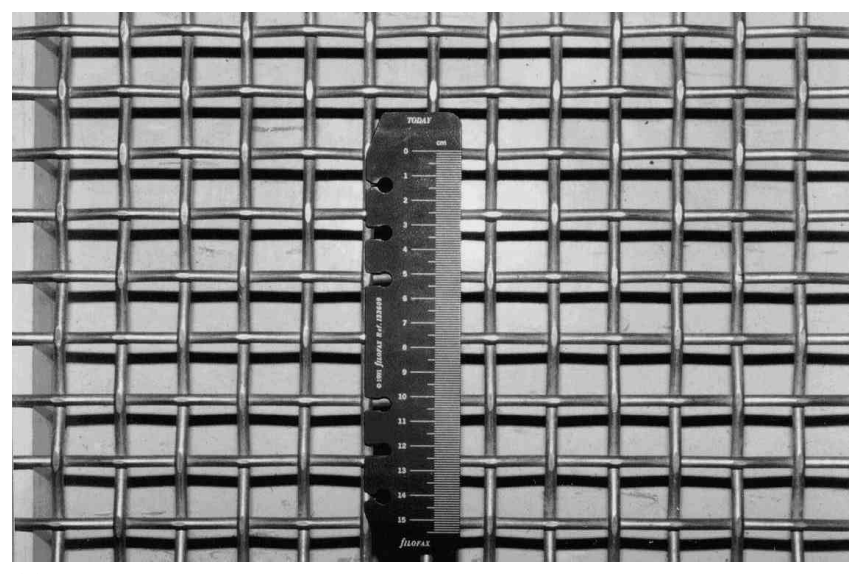

(c)

Fig. 1. Floor Surfaces. (a) Wood battens. (b) Plastic battens (plastic tiles) (c) Steel mesh.

\section{$2.4 \quad$ Experimental procedure}

The shearers wore 'shearing moccasins' and were instructed to drag the sheep at constant speed across the force plate. Force was measured with a $900 \mathrm{~mm}$ by $600 \mathrm{~mm}$ Kistler 9287 3D force plate, fitted beneath the centre panel of flooring (see Figure 2). Data collection software was AP30 (Pearce, 1996).

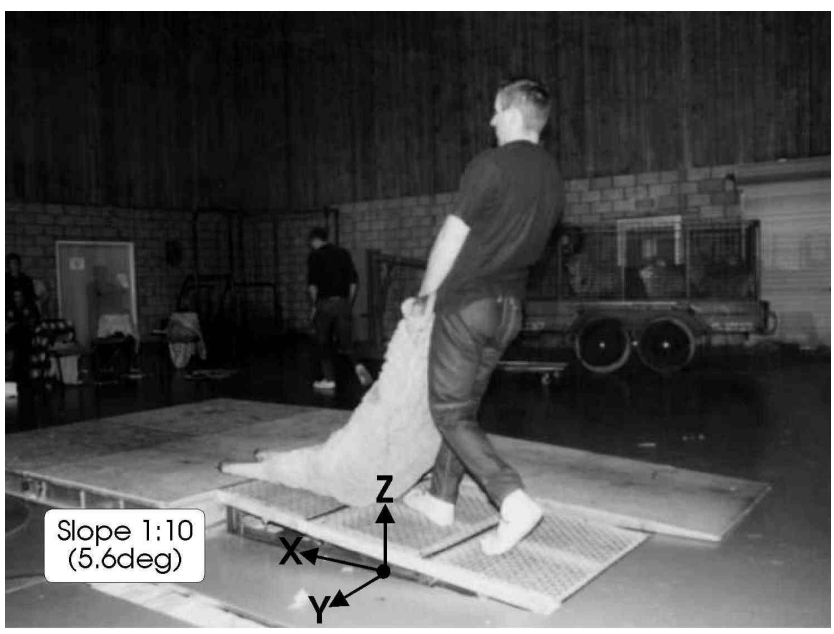

Fig. 2. Shearer on Force Plate and XYZ Co-ordinates

All data were represented in a global co-ordinate system relative to the ground (see Figure 2). Force in the horizontal longitudinal $(x)$, horizontal lateral $(y)$ and vertical $(z)$ directions was sampled for two seconds at $1000 \mathrm{~Hz}$ (2000 samples per trial). Data analysis was carried out using Microsoft ExcelV6 and MinitabV9. Each trial was videotaped.

\section{$2.5 \quad$ Response variables}

Three key response variables were derived and analysed:

1. Dragging force.

2. Maximum vertical ground reaction on the shearer.

3. Maximum rate of increase of the vertical ground reaction on the shearer.

Variable 1 was derived from data collected with the sheep on the force plate and variables 2 and 3 from data collected while the shearer was on the force plate.

Dragging force: The primary variable was the dragging force $F$ being exerted by the shearer on the sheep (see Figure 3). It was not feasible to measure this force directly. Rather, it was derived indirectly from force plate measurements of the ground reaction forces $R$ and weights $W$. Because the sheep was being passively dragged, data collected while the sheep was on the force plate were less subject to impulse effects than data collected while the shearer was on the force plate. For this reason, sheep-based data were used to estimate a steady state average dragging force.

The dragging force $F$ was calculated as follows:

$$
F=\sqrt{R_{x}^{2}+R_{y}^{2}+\left(W-R_{z}\right)^{2}}
$$

where $R$ is the ground reaction force and $W$ the weight of the sheep.

This best available estimate of the force being applied by the hands of the shearer is predicated on the 


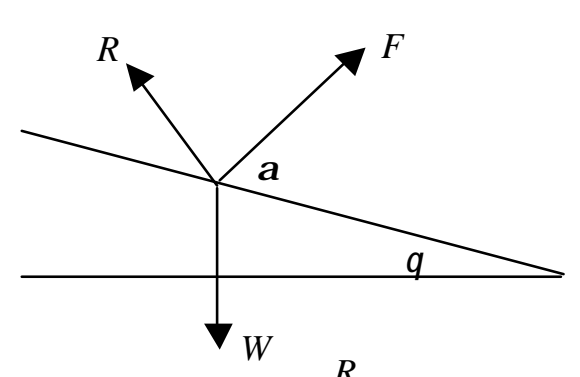

(a)

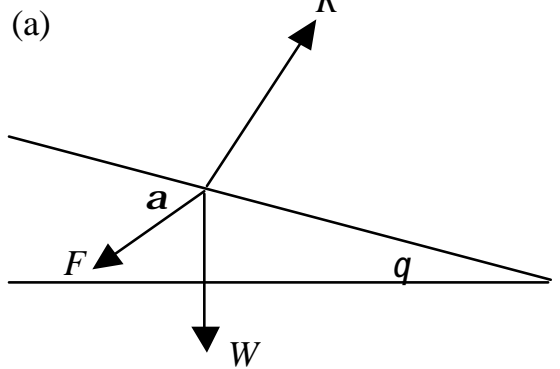

(b)

Fig. 3. Force Diagrams (a) Forces on Sheep. (b). Forces on Shearer.

$F=$ dragging force; $R=$ ground reaction; $W=$ weight $\theta=$ angle of inclination of floor; $\alpha=$ angle of inclination of drag to floor

assumptions that the sheep were inelastic and moving at constant velocity. Both assumptions are regarded as reasonable approximations. A trace of this variable, plotted over the $2000 \mathrm{~ms}$ of data collection, was visually inspected to identify a section of $100 \mathrm{~ms}$ duration in which the process was in a steady state, and a mean value was calculated.

Maximum vertical ground reaction on shearer and Maximum rate of increase of vertical ground reaction on shearer: The data measured while the shearer was on the plate had a more dynamic characteristic. The maximum value of the vertical ground reaction $R_{z}$ and the maximum rate of increase of $R_{z}$ were chosen as indicators of the impulsive forces exerted on the shearer's body. The maximum vertical ground reaction was estimated directly from the trace of $R_{z}$, after first smoothing it with a moving window of $40 \mathrm{~ms}$ duration to remove any spurious high frequency transients induced within the measurement equipment. The smoothed trace $R_{z}$ of was then differenced and the maximum rate of increase determined from the difference trace.

\subsection{Ancillary variables}

Four further variables were calculated for the purpose of biomechanical modelling and to enable further exploration of the behaviour of the three key variables. These were:

4. Coefficient of kinetic friction.

5. Vertical angle of application of dragging force.

6. Normal component of ground reaction force on sheep.

7. Speed of shearer.
Coefficient of kinetic friction: The coefficient of kinetic friction $\mu_{k}$ is determined by the characteristics of the floor material and the wool of the sheep in sliding contact. It is the ratio of the parallel and normal components of the ground reaction force. It was calculated using the following formula.

$\mu_{k}=\frac{\sqrt{\left(R_{x} \cos \theta+R_{z} \sin \theta\right)^{2}+R_{y}^{2}}}{R_{z} \cos \theta-R_{x} \sin \theta}$

where $R$ is the ground reaction force, and $\theta$ the angle of inclination of the surface $\left(0^{\circ}\right.$ or $\left.5.6^{\circ}\right)$

Angle of application of dragging force: This is the angle between the dragging force vector and its projection onto the floor surface (see Figure 3), calculated by

$\alpha=\tan ^{-1}\left(\frac{R_{x} \sin \theta-\left(R_{z}-W\right) \cos \theta}{\sqrt{\left(R_{x} \cos \theta+\left(R_{z}-W\right) \sin \theta\right)^{2}+R_{y}^{2}}}\right)$

where $R$ is the ground reaction force, $W$ the weight of the sheep, and $\theta$ the angle of inclination of the surface $\left(0^{\circ}\right.$ or $\left.5.6^{\circ}\right)$.

Normal component of ground reaction force on sheep: This variable is the denominator of the formula for $\mu_{k}$ :

$R_{n}=R_{z} \cos \theta-R_{x} \sin \theta$

where $R$ is the ground reaction force, and $\theta$ the angle of inclination of the surface $\left(0^{\circ}\right.$ or $\left.5.6^{\circ}\right)$

Speed of shearer: Videotapes of each trial were examined and the shearer's average speed was calculated by measuring the time (the number of video frames) taken by an identifiable point on the body of the sheep to traverse the test surface.

\subsection{Statistical analysis}

Each of the three key dependent variables was analysed with respect to four factors: the key experimental factors (floor texture and slope), and two subject-related factors (shearer and sheep). The shearer factor was further broken down by days, and into full-time/part-time, introducing a nested aspect into the design. Multi-factorial analyses of variance (ANOVAs) were undertaken, with appropriate representation of fixed and random effects factors and crossed and nested terms. By omitting non-significant factors and interactions, more parsimonious models were developed. Supplementary analyses of covariance were also carried out, involving dragging speed and coefficient of friction as covariates. Statistical significance was set at $\mathrm{p}<0.05$. Post hoc multiple pairwise comparisons used the Tukey honestly significant difference (HSD) criterion.

The validity of the statistical assumptions underlying the ANOVAs (normally distributed random errors, homogeneity of error variance across experimental conditions, sphericity of error covariance across 
repeated measures on the same subjects) were assessed by analysis of residuals and standard statistical tests. Whilst there were some violations of these assumptions, on the basis of a number of re-analyses and standard adjustments to degrees of freedom, it was assessed that these violations were inconsequential. Because the key results were very clear-cut, even the most conservative adjustments did not change the conclusions.

The reported results relating to the effects of the two key experimental factors (floor textures and slopes) were derived from ANOVA models which included main effects for slopes, textures, sheep and shearers, and a slope-texture interaction. In each case, the reported standard deviations are based on the tabulated two-factor (slope-texture) classification, but the F-tests and Tukey post hoc criteria are based on the residual mean squares from the four-factor model.

\subsection{Biomechanical modelling}

The videotape of the experiment showed that a posture like that shown in Figure 4 was most often adopted. This posture was modelled using the University of Michigan's 3D Static Strength Prediction Program ( $3 D$ SSPP). The program has been reported by Chaffin (1997) to be a valid predictor of strength capabilities.

\section{Results}

Not unexpectedly, there were statistically significant differences between shearers and between sheep for all dependent variables. When the heights and weights of shearers were incorporated as covariates, they accounted for much of the differences between shearers.

\subsection{Dragging force}

Table 2 shows results for the dragging force by texture and slope. There were significant differences between textures $(\mathrm{F}(4,379)=31.70, \mathrm{p}<0.0005)$. Using the Tukey HSD criterion, any two means that differ by more than $8.8 \mathrm{~N}$ were significantly different at the 0.05 level. Thus the mean for wooden battens at right angles did not differ significantly from either of the two means for plastic battens. All other pairwise differences were statistically significant. There was a significant difference between slopes $(\mathrm{F}(1,379)=172.54, \quad \mathrm{p}<0.0005) \quad$ but no significant texture-slope interaction $(\mathrm{F}(4,379)=0.22, \mathrm{p}=0.930)$.

The texture with the lowest mean dragging force was wooden battens parallel to the drag (horizontal: $388 \mathrm{~N}$; slope: $359 \mathrm{~N})$. The texture with the highest mean dragging force was steel mesh (horizontal: $423 \mathrm{~N}$; slope: 394N).

\subsection{Maximum vertical ground reaction and maximum rate of increase of vertical ground reaction}

Neither floor material nor slope had any statistically significant effect on either of these variables. There were some significant differences between shearers. An analysis of covariance with speed as a covariate showed that these were partly attributable to differences in the dragging speeds of different shearers.

\subsection{Coefficient of kinetic friction}

Table 3 shows results for the coefficient of friction by texture and slope. There are significant differences between textures $(\mathrm{F}(4,379)=907.36$, $\mathrm{p}<0.0005)$. Using Tukey HSD, any two means which differed by more than 0.019 were significantly different at the 0.05 level.
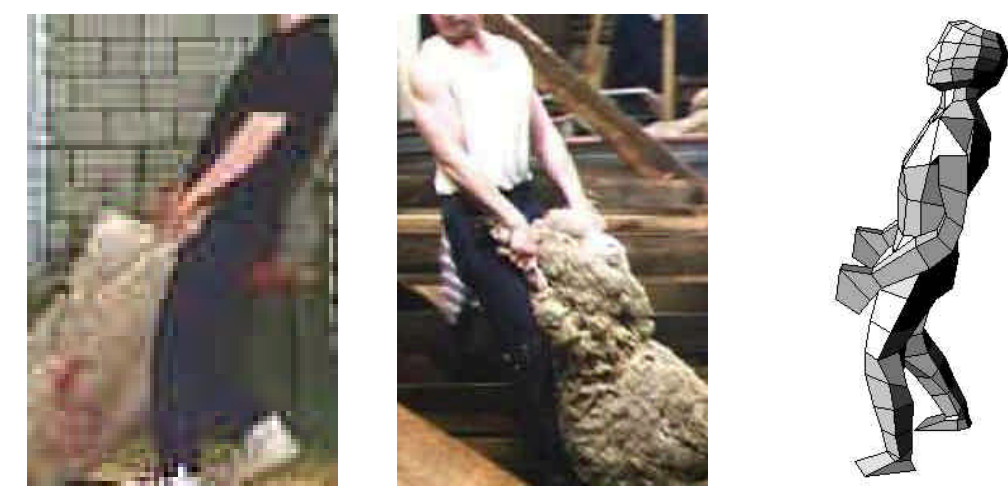

Fig. 4. Typical Dragging Postures: from the research (left); from an actual shearing shed (centre); an image from the biomechanical modeling software (right). 
Table 2

Dragging Force on Sheep $(\mathrm{N})$ : by Texture and Slope ${ }^{\mathrm{a}}$

\begin{tabular}{|c|c|c|c|c|c|}
\hline \multirow[b]{2}{*}{ Texture } & \multicolumn{2}{|c|}{ Slope $=0^{\circ}$} & \multicolumn{2}{|c|}{ Slope $=5.6^{\circ}$} & \multirow{2}{*}{$\begin{array}{l}\text { Both } \\
\text { slopes } \\
\text { Mean }\end{array}$} \\
\hline & Mean & SD & Mean & $\mathrm{SD}$ & \\
\hline Wood: Parallel & 388.2 & 28.0 & 359.2 & 31.8 & 373.7 \\
\hline Wood: At right angles & 400.4 & 22.4 & 376.4 & 29.2 & 388.4 \\
\hline Plastic: Parallel & 395.6 & 26.4 & 370.1 & 30.9 & 382.9 \\
\hline $\begin{array}{l}\text { Plastic: At right } \\
\text { angles }\end{array}$ & 405.4 & 24.7 & 378.9 & 31.4 & 392.2 \\
\hline Steel Mesh & 422.8 & 21.2 & 394.1 & 26.3 & 408.4 \\
\hline All textures & 402.5 & & 375.7 & & \\
\hline
\end{tabular}

a Sample size $n=40$ for each of the 10 texture-slope combinations

Table 3

Coefficient of Friction: by Texture and Slope ${ }^{a}$

\begin{tabular}{llllll}
\hline & \multicolumn{2}{l}{ Slope $=0^{\circ}$} & \multicolumn{2}{l}{ Slope $=5.6^{\circ}$} & $\begin{array}{l}\text { Both } \\
\text { slopes } \\
\text { Texture }\end{array}$ \\
\cline { 2 - 5 } & Mean & SD & Mean & SD & Mean \\
\hline Wood: Parallel & 0.507 & 0.045 & 0.484 & 0.047 & 0.496 \\
Wood: At right angles & 0.606 & 0.035 & 0.585 & 0.040 & 0.595 \\
Plastic: Parallel & 0.620 & 0.034 & 0.596 & 0.025 & 0.608 \\
Plastic: At right & 0.688 & 0.049 & 0.645 & 0.043 & 0.666 \\
$\begin{array}{l}\text { angles } \\
\text { Steel Mesh }\end{array}$ & 0.928 & 0.066 & 0.858 & 0.081 & 0.893 \\
& & & & & \\
All textures & 0.670 & & 0.633 & & \\
\hline
\end{tabular}

a Sample size $n=40$ for each of the 10 texture-slope combinations

Thus all pairwise differences between textures were significant except for wood at right angles versus parallel plastic battens. The texture with the lowest mean coefficient of friction was wood battens oriented parallel to the direction of the drag. The texture with the highest mean coefficient of friction was steel mesh.

There was a significant difference between slopes $(\mathrm{F}(1,379)=68.09, \mathrm{p}<0.0005)$ and a significant textureslope interaction $(\mathrm{F}(4,379)=4.54, \mathrm{p}=0.001)$. This interaction was only marginally significant after adjustment for repeated measures effects. The relationship between coefficient of friction and the slope is discussed below at Section 4.5.

\subsection{Other ancillary variables}

The ancillary variables vertical angle of application of dragging force and normal component of ground reaction force on sheep were derived for the purpose of secondary analyses, the results of which are reported in context in Section 4. The ancillary variable speed of shearer has been similarly reported in Section 3.2.

\subsection{Biomechanical modelling}

Fig. 4 shows the typical posture adopted while dragging the sheep in the experiment (left), an example of an actual shearer at work (centre) and an image from the biomechanical modelling software (right). Applying the greatest mean dragging force observed
(423N at an angle of $15^{\circ}$ on horizontal steel mesh - see Tables 2 and 5) to this model resulted in an L5-S1 spinal compression of $1297 \mathrm{~N}$, well below the NIOSH limit of 3400N (Waters et al., 1993). At this angle and in the posture modelled a hand force magnitude of about $1100 \mathrm{~N}$ is necessary before the spine compression reaches $3400 \mathrm{~N}$. The model also produces percent capabilities for various joints. The most critical are the elbow (78\% capable) and knee (82\% capable). Less critical are shoulder (98\% capable), torso (99\% capable; consistent with the spinal compression results), hip (97\% capable) and ankle (98\% capable).

\section{Discussion}

The discussion has been formulated with reference to the conceptual model of Hoozemans et al (1998). This model integrates exposure to external factors (work situation, actual working method, posture, movement and external forces), resultant internal (mechanical) exposure, acute responses, long term effects and work capacity. The discussion will also acknowledge the frameworks outlined by Winkel and Mathiassen (1994) and Hoozemans et al (1998). Winkel and Mathiassen (1994) proposed that exposure to work related factors can be explored through examining work intensity (amplitude and direction), frequency and duration. The review by Hoozemans et al. (1998) outlined the perspectives of epidemiology, psychophysics, physiology and biomechanics.

In terms of these frameworks, it can be seen that the current study was motivated by epidemiological evidence, and sought to understand work intensity during shearing through modifying aspects of external exposure and examining aspects of both external and internal exposure. Specifically, the study sought to determine the impact of factors that alter the actual work situation (floor slope and texture) on the forces exerted, as aspects of external exposure, and the resultant internal exposure. The exerted forces were explored via an examination of psychophysical factors. That is, the forces exerted when performing the work task under the various floor slope and texture conditions, were related to the maximum acceptable forces. Internal exposure was examined via the biomechanical estimation of L5/S1 compression. Specific physiological measures were not made during the study.

\subsection{Psychophysical perspectives}

\subsubsection{Dragging force}

The minimum mean dragging force was achieved using a sloping surface constructed of wooden battens arranged parallel to the direction of the drag. But whilst the central aim of the study was to compare the different floor surfaces, the actual magnitude of the forces also warrants examination. Since the number of sheep shorn per day by a professional shearer can be

Note: This paper is John Culvenor's version reprinted at www.culvenor.com with permission of Elsevier Science. There may be slight variations (pagination, typographical, etc) between this version and the published version (Applied Ergonomics, vol. 33, pp. 523-531). 
in excess of 200, injuries are more likely to be the result of the sustained nature of the work-task rather than the impact of a single instantaneous act. In such situations it is important to consider the cumulative impact of the forces on health and safety (Kumar, 1994; Mair et al., 1996). The mean forces (Table 2), which ranged from $359 \mathrm{~N}(36.6 \mathrm{~kg})$ to $423 \mathrm{~N}(43.2 \mathrm{~kg})$ were compared to the maximum acceptable limits for sustained pulling forces (Snook and Ciriello, 1991) reproduced in part in Table 4. Because of the near-vertical dragging angle employed, reference was also made to an accompanying table for lifting forces, but the conclusions drawn below were unchanged.

In terms of the parameters in Table 4 , the length of drag from within the catching pen to the shearing workstation is typically between $2.1 \mathrm{~m}$ and $7.6 \mathrm{~m}$. The task frequency is typically one sheep every $2-5 \mathrm{~min}$. Table 4 shows that regardless of the floor material or slope, the mean forces were close to or above the maximum figures for the $10^{\text {th }}$ percentile (i.e. the most capable 10\%) of men. Thus dragging sheep repetitively is a difficult task, within the capability of only the most able men, and too physically demanding for almost all women. Clearly, the forces involved are at the extreme of what is acceptable for an occupational activity. The findings here, which substantiate a difference in the order of $15 \%$ between the best floor tested and the worst floor tested, are thus of great practical importance.

Some caution must be exercised in drawing these conclusions. The results obtained were based on an indirect estimate of the force exerted by the shearer, which is predicated on the assumption of an inelastic sheep being dragged at constant velocity. Whilst every effort was made to ensure that the latter condition was achieved, no quantitative assessment has been made of the effect of any departures from either of these assumptions.

Another issue is that the initial force required to begin motion exceeds the steady-state dragging force. Calculation of this initial force from force plate measurements was infeasible because estimates of acceleration and elasticity of the sheep would be required.

\section{Table 4}

Maximum acceptable forces of pull (kg) for males \& (females) for pull height of $95 \mathrm{~cm}$ (males) and $89 \mathrm{~cm}$ (females) (from Snook \& Ciriello 1991)

\begin{tabular}{lllll}
\hline Pull Distance & $2.1 \mathrm{~m}$ & \multicolumn{3}{l}{$7.6 \mathrm{~m}$} \\
\cline { 2 - 5 } Frequency & $2 \mathrm{~min}$ & $5 \mathrm{~min}$ & $2 \mathrm{~min}$ & $5 \mathrm{~min}$ \\
\hline $90^{\text {th }}$ Percentile & $17(10)$ & $19(11)$ & $14(9)$ & $16(10)$ \\
$50^{\text {th }}$ Percentile & $27(17)$ & $31(19)$ & $22(15)$ & $25(16)$ \\
$10^{\text {th }}$ Percentile & $37(24)$ & $42(26)$ & $31(21)$ & $34(23)$ \\
\hline
\end{tabular}

From this perspective, our conclusions are clearly conservative, since our results under-estimate the peak stresses. Importantly, the batten orientation which resulted in the lowest dragging force is also favoured by shearers for another reason. Sheep catch their toes much less in the 'parallel' batten floor than they do with steel mesh or with battens at right angles to the drag, resulting in a reduction in the effort expended tipping sheep over.

\subsubsection{Relationship between coefficient of kinetic friction and dragging force}

The effect of floor surface and slope on the coefficient of friction was examined in order to understand the factors affecting the dragging force. On both sloping and horizontal floors, the coefficient of friction increased by some 80 percent from its minimum value for parallel wooden battens to its maximum value for steel mesh, compared to an increase of only 10 percent in the dragging force. We now explore the reason for this difference.

On a horizontal surface, the relationship between the dragging force $F$, coefficient of friction $\mu_{k}$, sheep weight $W$, and drag angle $\alpha$ is given by

$$
F=\frac{\mu_{k} W}{\cos \alpha+\mu_{k} \sin \alpha}
$$

when $\alpha=90^{\circ}$ (i.e. lifting the sheep), $F$ reaches a maximum value equal to $W$, and is independent of the coefficient of friction. At the opposite extreme, when $\alpha=0^{\circ}$ (i.e. a horizontal force), then $F=\mu_{k} W$. This is a lower force (providing $\mu_{k}<1$ ) but requires a posture not conducive to dragging. If shearers did drag sheep in this manner, the force required on different surfaces would change in direct proportion to the coefficient of friction.

In fact, the dragging force in all cases was applied only some $10-15^{\circ}$ away from the vertic al (Table 5), that is, with a substantial component of lift. Because the body angle adopted by the shearers, consistent with comfort and efficiency, was close to the vertical, the dragging force is not greatly dependent on the coefficient of friction, hence the relatively smaller differences between dragging forces on different surfaces.

\subsubsection{Dependence of the coefficient of kinetic friction on slope}

For each floor texture, the coefficient of friction was found to be some 5 to 10 percent lower on the $5.6^{\circ}$ slope than on the horizontal (Table 2). This is thought to be due to greater compaction of the wool on the sloping floor. Because shearers maintained the same drag angle relative to the vertical under both conditions (Table 5), the drag angle relative to the normal to the floor surface was less when the floor was sloping, resulting in an increase in the component of the ground reaction force normal to the floor surface in this case (Table 6), and hence, it is conjectured, 
increased compaction of the wool. An analysis of covariance confirmed directly that the coefficient of friction decreased as the normal component of the ground reaction force increased $(\mathrm{F}(1,388)=40.08$, $\mathrm{p}<.0005)$.

Despite the relatively high forces exerted, none of the shearers slipped during the dragging task. Slip hazards occur with horizontal hand forces and low coefficient of friction (Resnick and Chaffin,1995). Lee et al. (1992) reported that the minimum coefficient of friction required to avoid slippage decreased as hand height increased. In the present study, the upright dragging posture resulted in hand heights of around $90 \mathrm{~cm}$ and relatively small horizontal components of the hand force. The reported coefficients of friction, between the wool and the floor surfaces, were moderate to high, and well above the minimum value of 0.31 reported by Lee et al. (1992) as being required to avoid slippage with a hand height of $66 \mathrm{~cm}$. The coefficients of friction between the shearing moccasins and the floor was not measured. We expect it would be lower than between the wool and the floors, but since no slipping occurred, it was clearly sufficient.

\section{Table 5}

Vertical Angle of Dragging Force (Degrees from Vertical): by Texture and Slope ${ }^{\mathrm{a}}$

\begin{tabular}{|c|c|c|c|c|c|}
\hline \multirow[b]{2}{*}{ Texture } & \multicolumn{2}{|c|}{ Slope $=0^{\circ}$} & \multicolumn{2}{|c|}{ Slope $=5.6^{\circ b}$} & \multirow{2}{*}{$\begin{array}{l}\text { Both slopes } \\
\text { Mean }\end{array}$} \\
\hline & Mean & $\mathrm{SD}$ & Mean & $\mathrm{SD}$ & \\
\hline Wood: parallel & 11.0 & 2.9 & 12.2 & 2.4 & 11.6 \\
\hline Wood: at right angles & 11.8 & 2.4 & 11.6 & 2.6 & 11.7 \\
\hline Plastic: parallel & 12.9 & 3.3 & 13.1 & 2.7 & 13.0 \\
\hline Plastic: at right angles & 13.1 & 3.2 & 12.8 & 2.7 & 13.0 \\
\hline Steel mesh & 14.8 & 3.1 & 16.2 & 3.3 & 15.5 \\
\hline All textures & 12.7 & & 13.2 & & \\
\hline
\end{tabular}

Table 6

Normal Component of Ground Reaction Force on Sheep (N): by Texture and Slope ${ }^{\mathrm{a}}$

\begin{tabular}{|c|c|c|c|c|c|}
\hline \multirow[b]{2}{*}{ Texture } & \multicolumn{2}{|c|}{ Slope $=0^{\circ}$} & \multicolumn{2}{|c|}{ Slope $=5.6^{\circ}$} & \multirow{2}{*}{$\begin{array}{c}\text { Both slopes } \\
\text { Mean }\end{array}$} \\
\hline & Mean & SD & Mean & SD & \\
\hline Wood: parallel & 145.2 & 32.3 & 166.8 & 31.2 & 156.0 \\
\hline Wood: at right angles & 134.4 & 23.8 & 150.8 & 28.9 & 142.4 \\
\hline Plastic: parallel & 140.7 & 29.5 & 156.2 & 25.4 & 148.4 \\
\hline $\begin{array}{l}\text { Plastic: at right } \\
\text { angles }\end{array}$ & 131.5 & 24.2 & 148.0 & 29.7 & 139.9 \\
\hline Steel mesh & 117.8 & 23.2 & 137.2 & 26.5 & 127.4 \\
\hline All textures & 133.9 & & 151.9 & & \\
\hline
\end{tabular}

Slipping would be more likely to occur when accelerating the sheep as the forces would be greater. In this experiment the sheep was accelerated on a level plywood surface, not on the tested surface. However, after the experiment the sloping parallel batten floor was trialled in two shearing sheds. No problem with slipping was noted.

\subsection{Biomechanical perspectives}

From the results reported in section 3.5 , it would seem that the risk of joint injury is largely confined to the elbow and knee. The load caused by one drag on joints other than the elbow and knee is not particularly problematic, a result which might seem prima facie to contradict the proximity of the pulling forces to the maximum acceptable limits of Snook and Ciriello (1991). In particular, the L5-S1 spinal compression of $1297 \mathrm{~N}$ was well below the NIOSH limit of $3400 \mathrm{~N}$ (Waters et al., 1993). However the crucial difference is that the Snook and Ciriello criteria relate to sustained effort, whilst the biomechanical analysis and the NIOSH standards apply to instantaneous forces. Kumar (1994), Mair et al. (1996) and McGill (1997) have pointed out that the effect of fatigue may reduce the threshold force required to induce an injury. Given the repetitive nature of the dragging task in shearing, the cumulative effect in terms of energy expenditure may increase the risk of injuries to joints other than the elbow and knee.

\subsection{Physiological perspectives}

When dragging sheep over a fixed distance, there is a direct relationship between the force of drag and the energy demand of the task, and any reduction in the required force will lead to lower energy expenditure. A shearer can shear up to 200 sheep per day and these animals can often weigh $60 \mathrm{~kg}$ and sometimes up to $80 \mathrm{~kg}$. Each must be dragged from the catching pen to where the shearing takes place. The generally high level of energy expenditure associated with dragging sheep was demonstrated by Payne et al. (2002). They reported that the average steady state energy cost of dragging sheep on a smooth, flat surface was 2.42 $1 . \mathrm{min}^{-1}$ or $58.3 \%$ of $\mathrm{VO}_{2} \max$.

\section{Conclusion}

In conclusion, of the range of floor surfaces and angles examined, the optimum floor is a sloping surface (1:10 as tested) constructed of wooden battens arranged parallel to the direction of the drag. These relatively inexpensive modifications have the potential to substantially improve the safety of shearing as it is likely that the risk of injury will be reduced through a reduction of dragging force by up to $15 \%$. 
It is recommended that such a floor be installed where practicable. Both a slope and a change to the orientation of battens require some alteration to the subfloor structure, but this should not be very difficult or expensive. However, the ramifications of a slope, insofar as it affects the way sheep enter the pen and the way gates operate may be more problematic. These issues relate to individual shearing sheds and would have to be addressed on an individual basis.

\section{Acknowledgements}

The authors acknowledge the contribution of the National Occupational Health and Safety Commission who funded the unpublished study upon which this paper is based (Payne, et al. 1998); and Haisam Askari, Robert Freeman, Rod Hall, Keith McElroy and John Pryor, who contributed to the conduct of the study. We also acknowledge the enthusiasm and the insights of the participating shearers. Thanks too to two anonymous reviewers whose comments led to substantial improvements in the paper.

\section{References}

Australian Workers' Union (Vic.), 1993. Code of Practice for the Shearing Industry (Health, Safety \& Welfare Standards). AWU, Carlton South, Australia.

Ayoub, M.M., McDaniel, J.W., 1974. Effects of operator stance on pushing and pulling tasks. AIIE Trans. 6, 185-195.

Chaffin, D.B. 1997. Development of a computerized human static strength simulation model for job design. Human Factors Ergonom. Manuf. 7: 305-322.

Chaffin, D.B., Andersson, G.B.J., 1983. Volitional postures during maximal push/pull exertions in the sagittal plane. Hum. Factors $25,541-550$.

Ciriello, V.M., Snook, S.H., Blick, A.C., Wilkinson, P.L., 1990. The effects of task duration on psychophysically determined maximum acceptable weights and forces. Ergonomics 33, 187 200.

Cole, F.., Foley, G., 1995. Occupational Health and Safety Performance Overviews, Selected Industries: Issue No. 9, Agriculture and Services to Agriculture Industries. AGPS, Canberra.

Culvenor, J., Cowley, S., Freeman, R., Harvey, J., Lawrance, M., McElroy, K., Payne, W., Pryor, J., Stuart, D., Williams, R. 1997. The Ergonomics of Sheep Shearing. In: Productivity Ergonomics and Safety: The Total Package, International Workplace Health \& Safety Forum and 33rd Ergonomics Society of Australia Conference, Gold Coast, available on CD ROM

http://www.whs.qld.gov.au/conference/ergonomic97/culvenor.pdf

Freeman, R.B 1991, Helping Woolgrowers Contain Shearing Costs, University of Melbourne.

Health and Safety Organisation, Victoria, 1995. The Sheep Shearing Project. HSO, Melbourne.

Hoozemans, M.J.M, van der Beek, A.J., Frings-Dresen, M.H.W., van der Molen, H.F., 2001. Evaluation of methods to assess push/pull forces in a construction task. Appl. Ergonomics 32, 509-516.

Hoozemans, M.J.M, van der Beek, A.J., Frings-Dresen, M.H.W., Van Dijk, F.J.H., van der Wjoude, L.H.V., 1998. Pushing and pulling in relation to musculoskeletal disorders: a review of risk factors. Ergonomics 41, 757-781.
Looze, M.P. de, Urlings, I.J.M., 2001. Towards successful physical stress reducing products: an evaluation of seven cases. Appl. Ergonomics 32(5) 525-534.

Kumar, S., 1994, A conceptual model of overexertion, safety and risk of injury in occupational settings. Human Factors 36(2) 197-209.

Kumar, S., Chaffin, D.B., Redfern, M., 1988. Isometric and isokinetic back and arm lifting strengths: devices and measurement. J. Biomech. 21, 35-44.

Lee, K.S., Chaffin, D.B. Herrin, G.D., Waikar, A.M., 1991. Effect of handle height on lower-back loading in cart pushing and pulling. Appl. Ergonomics 22, 117-123.

Lee, K.S., Chaffin, D.B., Parks, C., 1992. A study of slip potential during cart pushing and pulling. IIE Trans. 24 (5), 139-146.

Mair, S.D., Seaber, A.V., Glisson, R.R., Garrett, W.E., 1996. The role of fatigue in susceptibility to acute muscle strain injury. The American Journal of Sports Medicine 24(2) 137-143.

McGill, S.M. 1997. The biomechanics of low back injury: Implications on current practice in industry and the clinic. $J$. Biomechanics 30, 465-475.

National Occupational Health and Safety Commission, 1990. National Code of Practice for Manual Handling. AGPS, Canberra, available www.nohsc.gov.au.

Payne, W.R., Culvenor J., Lawrance M., Harvey J.T., Cowley S., Stuart D., Williams R., 2002. Reducing the energy cost and decreasing the risk of injury during sheep sheering by altering the path of sheep drag. The Journal of Occupational Health and Safety (in press).

Payne, W., Askari, H., Cowley, S., Culvenor, J., Freeman, R., Hall, R., Harvey, J., Lawrance, M., McElroy, K., Pryor, J., Stuart, D., Williams, R., 1998. The Ergonomics of Sheep Shearing: Reducing Back Injuries and Energy Expenditure in Sheep Shearing through the Development of Practical Modifications to Shed Layout, Final Report to the National Occupational Health and Safety Commission, unpublished, available www.culvenor.com.

Pearce, A., 1996. AP30 Software System, Developed as part of a departmental biomechanics program for the Department of Human Movement and Exercise Science at the University of Western Australia.

Resnick, M.L. and Chaffin, D.B., 1995. An ergonomic evaluation of handle height and load in maximal and submaximal cart pushing. Appl. Ergonomics 26, 173-178.

Snook, S.H.., Ciriello, V.M., 1991. The Design of Manual Handling Tasks: Revised Tables of Maximum Acceptable Weights and Forces. Ergonomics 34 (9), 1197-1213.

Stuart, D., 1991, The Physical Demands of Sheepshearing - with Particular Reference to the Physical Fitness of Shearers. In: Farmsafe 88: Papers and Proceedings $f$ the Farmsafe 88 Conference, University of New England. AGPS, Canberra, pp. 419-427.

Van der Beek, A.J., Kluver, B.D.R., Frings-Dresen, M.H.W., 2000. Gender differences in exerted forces and physiological load during pushing and pulling of wheeled cages by postal workers. Ergonomics 43(2), 269-281.

Waters, T.R., Putz-Anderson, V., Garg, A., Fine, L.J., 1993. Revised NIOSH Equation for the Design and Evaluation of Manual Lifting Tasks. Ergonomics 36 (7), 749-776.

Webster, M.E.D., Lush, D.P., 1991. The Effect of Shearing and Crutching. In: Farmsafe 88: Papers and Proceedings of the Farmsafe 88 Conference, University of New England. AGPS, Canberra, pp. 449-453.

Winkel, J., Mathiassen, S.E., 1994. Assessment of physical work load in epidemiologic studies: concepts, issues and operational considerations, Ergonomics, 37, 979-988. 